\title{
Attitude Towards Zakah on Employment Income : Comparing Outcomes Between Single Score and Multidimensional Scores
}

\author{
KAMIL MD. IDRIS \\ School of Accountancy \\ Universiti Utara Malaysia \\ AHMAD MAHDZAN AYOB \\ School of Economics \\ Universiti Utara Malaysia
}

A) ABSTRACT

- Study on attitude towards regulated social activities have been carried out in many areas (such as tax and zakah payment). However, many of these studies applied a single score of attitude in their analyses. Such a procedure, to some researchers is considered less informative, especially in the study of a complex attitude which has several dimensions. Many researchers have suggested that attitude towards a complex object should be studied by decomposing the object or issue into smaller and less complex elements on the basis - of component parts, specific functions, or particular contexts. Thus, this paper offers a comparative study of outcomes between attitude measured by a single summative score and attitude measured by multidimensional factor scores. The object of attitude in this paper is zakah on employment income by eligible Muslim. In the first approach, a total of 24 items of attitude were used to represent the single score of attitude. In the second approach, principal component analysis with varimax ratation was first applied to determine the underlying dimensions of attitude. Each dimensian was then named and treated as a new variable, each measured by the factor scores. Both approach were applied separately to an analysis on - compliance behavior of zakah on employment income. Results suggest that attitude measured by multidimensionality scores is more informative as compared to the single summative score. Futher, the use of multidimensional scores in multivariate logistic regression improved the goodness of fit of the model over that of the single score of attitude. Thus, this improvement affects the interpretation of the whole model with respect to the relationship between the independent variables and the dependent variable, which is zakah compliance.

Key words: Attitude; Zakah; Compliance Behaviour. 
Much has been written abouthow attitudeinfluence regulated social activities. Studies in taxation and zakah have shown that attitude is significantly related to compliance behaviour. Attitude is one of the main variables in tax compli ance model (Fischer, Wartick, and Mark, 1992). Although much attention has been given on how attitude influences compliance behaviour, the variable attitude has not been fully explored. This is because many previous studies measured attitude only by a single score. A single score of attitude raises a dilemma as to whether attitude is a unidimensional or multidimensional concept (Mueller, 1986). In addition, the single attitude score does not provide sufficient information about a person's attitude (Sherif and Hovland, 1961). This is especially true in complex attitudinal objects(Mueller, 1986) such as attitude towards a person (Oskamp, 1991). Attitude towards taxation is considered as complex attitudinalobject.Similarly attitudetowardszakah on employment income is also considered as complex attitudinal object. Complex attitudinal objects require detailed study to provide better information (Sherif and Hovland, 1961).

In zakah system, the compliance of payment of zakah on employment income heavily relies on the positive attitude of Muslims towards zakah onemploymentincome and zakah institutions. This is because the zakah system in Malaysiadepends on theintegrity of individual Muslims to comply with the rules voluntarily in assessing their respective amount of zakah. However, there is no empirical study on attitude in zakah system to support this contention. Realizing that attitude can be measured using two approaches, i.e. summative single score and multidimensional factor scores, this 
paper offers some comparative empirical results with respect to attitude towards zakah on employmentincomeand their relationship with the compliance behaviour.

\section{PREVIOUS STUDY}

The role of attitude in compliance behaviour has been considered as necessary in many regulated social activities (Sutinen and Kuperan, 1999). In taxation for example, previous researchers have suggested that any serious effort to improve the compliance level should begin with improving taxpayers' attitude (Silver, 1995). This is because the attitude of a person towards a particular object may influence decision making (Mueller, 1986). Thus, many researchers have included attitude as one of the main variables in their compliance model (Jackson and Milliron, 1986; Fischer, et al.,1992; Hajah Mustafa, 1996; Tayib, 1998). In these studies, attitudes were found to be significantly related to compliance behaviour. However, there has been no attempt to study further the components of attitude towards taxation and their relationship with compliance behaviour. According to Lewis (1982), there was an attempt by Spicer and Lundstedt (1976) who studied components of attitude using factor analysis, but the study was focused on attitude towards tax evasion and not attitude towards taxation. A similar attempt was carried out by Eriksen and Fallan (1996). Although the study was called attitude towards taxation, the study primarily focused on tax evasion. Bobek (1997) carried out another study on attitude which focused on how a person's attitude towards taxation acts as a function to the fairness of the tax system. She had identified two attitude functions, i.e. valueexpressive function and utilitarian function. Both were measured by using a single score. However, the findings of the study showed that there was no significant relationship between the variables and the fairness of the tax system. Many other studies have also measured attitude by using a single score and tested against the dependent variable of compliance behaviour.

Studies on the components of attitude were also carried out in non-regulated social activities. For example, Dyer and Osborne (1996) reported that there were three components in the attitude towards agricultural programmes. These components were identified by using factor analysis. Similarly, Lawver and Fraze (1996) also used factor analysis to study attitude towards agricultural mechanical laboratory safety. Eight factors were identified in their study.

These previous studies, thus, motivate other researchers to study further the attitude towards zakah on employment income. However, it has to be dicided whether to measure attitude by a single score or multidimensional factor scores. In order to decide this, one has to understand the theory of attitude and the nature of attitude under study.

\section{ATTITUDE THEORY}

\section{Attitude Definition}

According to Mueller (1986), attitude is an important element in a person because it influences one to make decisions. In the planned behaviour theory, attitude becomes one of the 
major factors in predicting the behaviour of a person (Elliot, Timothy, and Robin, 1999). Attitude has been defined in many different ways and approaches. According to Alport (as cited in Oskamp, 1991):

\section{Anattitude is a mental or neural state of readiness, organised throughexperience, exerting a directive or dynamic influ- ence upon the individual's response to all objects and situations with which it is related.}

There are many definitions of attitude. However, according to Alport, the central feature of these definitions of attitude is the idea of readiness for response. This means that attitude is not a behaviour or something one does but rather it is a preparation for behaviour, a predisposition to respond in a particular way to the 'attitude object'. The term 'attitude object' is used to include things, people, places, ideas, actions, or situations, either singular or plural (Oskamp, 1991). Another point to note is the motivating or driving force of attitude. This driving force, according to Alport influences a person to behave in a certain way.

Psychology literature has identified two main theoretical viewpoints about the essential nature of attitude, i.e. tri-componential viewpoint and separate entities viewpoint (Oskamp, 1991). The former holds that attitude is a single entity but that it has three aspects or components, i.e. cognitive, affective, and behavioural components. In contrast, the second viewpoint holds that the three components are distinct, separate entities, which may be related or may not be related. Although these theories are common to re- searchers, different researchers conducted their studies by using different approaches. Sherif and Hovland (1961), for example, adopted a social judgement approach. Their major contribution to attitude theory and measurement is the concept of Attitude Latitude, that is, a range of attitudinal positions, which a person may accept or reject concerning a given issue. This concept stresses that the cognitive and affective components of attitude are inextricably intertwined during the process of making judgement about social objects.

\section{Complexity of Attitude}

Attitude towards an object can be studied by analysing its complex characteristics(Oskamp, 1991). Although there are three components embedded in attitude, each component can be ranged from simple to complex characteristics or they are mixed up with each other. Thus, the attitude score of two persons may be the same, but it may not reflect the true attitude of a person towards an object (Mueller, 1986). For example, two persons may have same moderate scores of attitude towards the mosque after answering several combinations of questions. However, one may be attracted to the mosque primarily for its spiritual qualities (association with god, heaven, morality and so forth), whereas the other may like the mosque primarily as an instrument for the fulfilment of social needs. For this reason, many researchers have suggested that attitude should be studied by dividing an object or issue into smaller and less complex elements (Mueller, 1986).

Simple attitude objects such as parking lots, pens, and oranges don't seem to raise suggestion of multidimensionality (Mueller, 
1986). These are relatively simple, single-function objects. As long as they fulfil the function well, they are liked and if they don't, they are disliked. On the other hand, more complex objects encompass more diverse opinions and thus more complex attitudes. For example one may like an automobile for its power, luxury, handling, and status but dislike its lack of economy, size and country of origin. Attitude towards zakah on employment income is con- sidered complex and accounts for further study to see its components and their relationship with compliance behaviour. Understanding the attitude of taxpayers may assist the taxation authorities in formulating taxation strategies to increase the level of compliance (Silver, 1995). This may also apply to zakah authorities.

\section{Research Question and Objectives}

- The purpose of this study is to gain underStanding of the impact of attitude scores on the compliance model by using two different approaches of attitude measurement. Although there may be many factors affecting the compliance behaviour of zakah payment, this paper focuses on the detailed aspect of attitude towards zakah on employment income. Thus, the following questions are related to this issue:

(a) What are the components of attitudes of qualified Muslim employees towards zakah on employment income?

(b) Does alternative approach (i.e. multidimensional factor scores) of measuring attitude furnish better outcome to the compliance model?
In order to answer the above questions the following specific objectives are proposed:

(a) To identify the various components in the attitude towards zakah on employment income;

(b) To ascertain whether the multidimensional factors approach yields better results to the compliance model.

\section{RESEARCH METHODOLOGY}

\section{Data Collection and Sample}

The unit of analysis in this study is the individual federal government employee who works in the state of Kedah and is subjected to scheduled tax deduction scheme. They are the employees who receive first-hand information through the state government's circulars, especially on matters that are gazetted to become law. The fatwa (religious decision) of zakah on employment income for the state of Kedah has been gazetted in 1986 (Mujaini Tarimin, 1995). Consequently, those employees who earn more than RM3,000 per annum after allowable deductions are subjected to zakah. However, in the income tax system, employees who earn RM15,000 per annum are generally subject to tax. This means that Muslim employees who pay income taxes are also automatically subject to zakah.

There were about 11,400 Muslim employees listed on such scheme as at $30^{\text {th }}$ June 2000. A systematic sample of 700 employees was selected. Since the name of respondents together with their respective departments was listed randomly, systematic sampling is justified. The names and office addresses were 
selected on every $16^{\text {th }}$ count $(11,400 / 700=16)$ starting from the first name. Hence, the first name selected was employee number $16^{\text {th }}$, followed by number $32^{\text {nd }}$ and so forth.

Survey questionnaires were mailed with a postage-paid return envelope to all respondents in the sample. The survey method is considered appropriate because it can include many socio-economic, demographic, and attitudinal variables (Andreoni, Errard, and Feinstein., 1998). After a month, a total of 383 respondents returned the questionnaires, which included 26 questionnaires returned unanswered and four questionnaires incomplete. The remaining questionnaires, i.e. 353, represent a response rate of $50 \%$. Data from these questionnaires were entered into computer using SPSS software for analysis. The number of respondents used in this analysis is close to the sample size suggested in Krjecie and Morgan's (as cited in Sekaran, 2000) sample size table, i.e. 370 (Sekaran, 2000). However, the size of the sample in this study exceeds the requirement suggested by Coakes and Steed (1999) and Roscoe (as cited in Sekaran, 2000). According to Coakes and Steed (1999), a sample size of 20 times of the number of variables under study is considered appropriate for the purpose of analysis using Factor Analysis and Regression. On the other hand, Roscoe's rule of thumb suggested that the appropriate sample size for analysis would be ten times or more than the number of variables in the analysis (Sekaran, 2000).

\section{Survey Instrument}

The only dependent variable in this study is the payment of zakah. Those who pay zakah are considered complying with the zakah law while those who do not pay are the noncomplying. Respondents were required to answer "yes/no" questions with regard to payments of zakah on employment income. This binary dependent variable is coded " 1 " for payment (compliance) and " 0 " for nonpayment (non-compliance).

Besides questions related to factors that are believed affecting the compliance behaviour, each questionnaire contained an instrument of 24 items of attitude statements, which were designed by using Likert's procedures. Initially these items were obtained by posing positive and negative statements of zakah on employment income from diverse groups of Muslim employees. These statements were collected by e-mail through uumnet and hizbinet (a Muslim eGroup that normally discusses religious matters). Within a week a total of 159 statements were obtained. Each statement was then processed and scrutinised in order to avoid any redundancy. After processing and editing, 29 items of attitude statements were listed, consisting of 15 positive statements and 14 negative statements. For example, a positive statement states "Zakah on employmentincomeshould be made obligatory to all qualified Muslim employees". A negativestatementstates "Zakah on employment income is a burden to Muslim employees." Each statement was then given a 5point Likert scale for the purpose of measurement. The scale ranges from 1 point ("Strongly Disagree") to 5 point ("Strongly Agree"). However, the scoring was reversed for the negative items for calculating the scale.

A pilot study was carried out on a small diverse group of employees (63 employees), to test the reliability and validity of the instrument. After thepilottest, sixmore items were dropped. 
The final number of items consists of 15 positive statements and 9 negative statements. These 24 items are then used to measure the construct of attitude towards zakah on employment income by taking a summated rating.

\section{Statistical Technique}

In the factor analysis, we chose Principal Component Analysis (PCA) followed by a varimax rotation of all theitems in the measures. This method is effective and widely used as a mean of exploring the interdependence among the variables (Kim and Mueller, 1978; Johnson and Wichern, 1992). Further, it leads to more parsimonious solution (Bennett and Bowers, 1976). - Consequently, a set of components of attitude was obtained. Each factor thathad an Eigenvalues of 1 or more is considered as significant (Hair et al., 1995) and treated as a new independent variable for further analysis in the study. Items - that had rotated factor loadings of 0.4 or higher are considered significant. Thus, any item that had factor loadings below 0.4 was excluded from the analysis. Besides performing factor analysis, data matrix was also examined to ensure that it had sufficient correlation to justify the application of factor analysis. Thus, the - Kaiser-Meyer-Olkin (KMO) measure of sampling adequacy and Bartlett's Test of Sphericity were used to quantify the appropriateness of factor analysis (Hair, et al. 1995).

A multivariate logistic regression analysis was conducted following the factor analysis. The new independent variables, i.e. components, obtained from the factor analysis were treated as part of a function of the payment of zakah on employment income (dependent variable). Factor scores of each component extracted from the factor analysis, were saved and used in the regression analysis. Thus, the following model was tested:

$$
\begin{aligned}
\operatorname{Logit}(P)= & a+b_{1} X_{1}+b_{2} X_{2}+b_{3} X_{3}+b_{4} X_{4}+b_{5} \\
& X_{5}+b_{6} X_{6}+b_{7} X_{7}+b_{8} X_{8} \\
& +b_{9} X_{9}+b_{10} X_{10}+b_{11} X_{11}+b_{12} A_{1}+b_{13} \\
& A_{2}+b_{14} A_{3}+b_{15} A_{4}+b_{16} A_{5}
\end{aligned}
$$

$\operatorname{Logit}(\mathrm{P})=\log$

where, $\quad\left[\frac{P}{1-P}\right]$

$\mathrm{P} \quad=$ Payment (coded as "1" for pay ment and " 0 " for nonpayment)

$x_{1}=$ Gender

$x_{2}=$ Age

$X_{3}=$ Number of dependants

$X_{4}=$ Income

$X_{5}=$ Perception on Zakah Law

$X_{6}=$ Perception on Zakah Enforcement

$\mathrm{X}_{7}=$ Knowledge Perception on Fairness

$X_{8}=$ Perceived Service Quality

$X_{9}=$ Promotional Exposure

$X_{10}=$ Religiosity Index

$X_{11}=$ Knowledge

$\mathrm{A}_{1}-\mathrm{A}_{5}=$ Attitude Components

For the purpose of significant test of the logistic model,Hosmer and Lemeshow's (1989) (as cited in Menard, 1995) procedure was used to determine whether the independent variables made better predictions of the dependent dichotomous variable (Menard, 1995). The coefficients obtained from this analysis show the strength and directions of the relationship between variables, and will not be used for predictive purposes. 


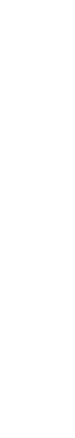

\section{Reliability and Validity of Instruments}

The reliability analysis of a measuring instrument determines the consistency with which the instrument is measuring the concept (Nunnally, 1978). There are several methods that can be used to assess reliability. However, for the present study, reliability is operationalized as internal consistency, which is the degree of intercorrelation among items that measure the same concept(Sekaran, 2000). The recommended measure of the internal consistency of a set of items is provided by Cronbach's Alpha (Nunnally, 1978; Churchill, 1979). Cronbach's alpha can be considered a perfectly adequate indication of the internal consistency. An alpha value of 0.70 or more is considered sufficient (Nunnally, 1978).

Having established the reliability of the attitude construct, its validity needs to be established. A measuring instrument is valid if it measures what it is intended to measure (Nunnally, 1978). For this purpose, two types of validity were adopted, i.e. content validity and construct validity. Content validity refers to the adequacy and representativeness of a set of items that tap the concept (Sekaran, 2000). The instrument developed in this study demonstrates the content validity of attitude since the selection of measurement items was based from the feedback of independent diverse group of people and tested in the pilot study. In addition, the measurement was also confirmed through both an exhaustive review of the literature and detailed evaluations by academicians and officers in charge of zakah.

For the purpose of construct validity, results produced from factor analysis wereevaluated by factor analysing the measurement. Construct validity refers to the degree to which a measure assesses the construct it is purported to assess (Peter, 1981). A construct measure is considered construct-valid to the degree that it assesses the magnitude and direction of a representative sample of the characteristics of the construct and to the degree that the measure is not contaminated with elements from the domain of other constructs or errors.

\section{RESULTS}

A Cronbach's alpha of 0.88 was obtained from the reliability test on the 24 items of attitude statements. This exceeded the Nunnally's (1978) reliability guidelines that considered alpha value of 0.7 and above as being sufficient. Examination of data matrix with $\mathrm{KMO}$ value of 0.9 and Bartlett's Test of Sphericity (Sig. $=0.000)$ indicated that the appropriateness of factor analysis was "marvelous" (Hair et al., 1995). The respondents consisted of $43 \%$ males and $57 \%$ females. The average age of respondents was 42 years old. The number of respondents who paid zakah on employment income was $123(35 \%)$. The remaining respondents failed to pay zakah.

\section{Factor Analysis}

Table 1, on page 55, shows the results of rotated components matrix in factor analysis. There are fivecomponents that have Eigenvalue of 1 or more. Component 1 has the highest Eigenvalue, i.e. 8.0. The percentage of the total variance from these five components is $59 \%$ and is regarded as satisfactory. The highest percentage of total variance comes from Component 1 , which accounts for $33.4 \%$. The five components are named respectively as Gen- 
eral Acceptability, Positive Acceptability, Uncertain Acceptability, Conditional Acceptability, and Technical Acceptability. Under the General Acceptability (6 items) the rotated factor loadings range from 0.42 to 0.83 . Positive Acceptability (7items) has rotated factorloadings that range from 0.46 to 0.7 . The rotated factor loadings for the Uncertain Acceptability (6 items) range from 0.47 to 0.7 . The Conditional ( 3 items) and Technical (2 items) Acceptability components have rotated factor loadings of 0.52 to 0.74 , and, 0.72 to 0.83 respectively.

Table 1

Rotated Component Matrix (N=353)

\section{Item No. Component}

$\begin{array}{lllll}1 & 2 & 3 & 4 & 5\end{array}$

General Acceptablility (6 items)

Must pay-responsibility in religion

Happy to pay

Zakah obligatory-condition fulfil

Zakah purify income received

Should long be implemented

When every scholar

.832

.811

.802

.745

.524

.416

Positive Acceptability (7 items)

Should be included in the school curriculum $\quad 20 \quad 691$

If not pay-feel liable to god

Appropriate to impose

Assessment is simple

If not pay-disobey one of the pillar of Islam

Tell others to pay

Still pay even though unclear

$\begin{array}{ll}7 & .458\end{array}$

\section{Uncertain Acceptability (6 items)}

Wait for a better system

Better pay zakah on savings than income

Conditional Acceptability (2 items)

Failure-should take action

$\begin{array}{rr}8 & .744 \\ 9 & .726 \\ 16 & .524\end{array}$

Consent to deduct monthly income

Should be informed in all states

Technical Acceptability (2 items)

Assessment not suitable-similar to tax

Computation is confusing

Extraction Method: Principal Component Analysis. Rotation Method: Varimax with

Kaiser Normalization.

a Rotation converged in 8 iterations.

Eigenvalue of the components $=1$ or more 
Table 2

Logistic Regression Analysis of Zakah on Employment Income (N=348)

Using Attitude Summative Single Score

\begin{tabular}{|c|c|c|c|c|c|}
\hline & & \multicolumn{4}{|c|}{ Classification Table } \\
\hline \multirow{5}{*}{ Step 1} & \multirow{4}{*}{$\begin{array}{l}\text { Observed } \\
\text { Payment }\end{array}$} & & \multicolumn{3}{|c|}{ Predicted } \\
\hline & & & \multicolumn{2}{|c|}{ Payment } & Percentage \\
\hline & & & Yes & No & \\
\hline & & Yes & 204 & 25 & 89.1 \\
\hline & Overal Percentage & No & 43 & 73 & $\begin{array}{r}62.9 \\
80.3\end{array}$ \\
\hline
\end{tabular}

a Constant is included in the model.

b The cut value is .500

Variables in Equation

\begin{tabular}{lccccccc}
\hline & $\begin{array}{l}\text { Coefficient } / \\
\text { Expected }\end{array}$ & $\mathbf{B}$ & $\begin{array}{c}\text { Standard } \\
\text { Deviation }\end{array}$ & Wald & df & Sig. & Exp(B) \\
\hline$X_{1}(1)$ & $\beta_{1} /-$ & .014 & .327 & .002 & 1 & .967 & .987 \\
$X_{2}$ & $\beta_{2} /+$ & .016 & .027 & .364 & 1 & .546 & 1.016 \\
$X_{3}$ & $\beta_{3} /-$ & .052 & .072 & .532 & 1 & .466 & 1.054 \\
$X_{4}$ & $\beta_{4} /+$ & .000 & .000 & .324 & 1 & .569 & 1.000 \\
$X_{5}$ & $\beta_{5} /+$ & .251 & .047 & 28.586 & 1 & $0.000^{* *}$ & 1.286 \\
$X_{6}$ & $\beta_{6} /+$ & -.017 & .058 & .084 & 1 & .773 & .983 \\
$X_{7}$ & $\beta_{7} /+$ & -.040 & .044 & .805 & 1 & .370 & .961 \\
$X_{8}$ & $\beta_{8} /+$ & .030 & .017 & 3.177 & 1 & .075 & 1.031 \\
$X_{9}$ & $\beta_{9} /+$ & .166 & .033 & 24.562 & 1 & $0.000^{* *}$ & 1.180 \\
$X_{10}$ & $\beta_{10} /+$ & -.051 & .024 & 4.631 & 1 & $0.031^{*}$ & .950 \\
$X_{11}$ & $\beta_{11} /+$ & .155 & .074 & 4.408 & 1 & $0.036^{*}$ & 1.167 \\
$A_{1}$ & $\beta_{12} /+$ & .062 & .015 & 17.660 & 1 & $0.000^{* *}$ & 1.064 \\
Constant & & -13.407 & 2.126 & 39.767 & 1 & .000 & .000 \\
\hline$X_{1}(1)$ & & & & & & & \\
\hline
\end{tabular}

$\mathrm{X}_{1}(1)=$ Male

$* / * *=(\mathrm{p} \leq 0.05) /(\mathrm{p} \leq 0.001)$

Model Summary: -2 LL = 281.633; Cox \& Snell $R^{2}=0.369$; Nagelkerke $R^{2}=0.512$

Hosmer and Lemeshow Test: Chi-squre $=10.034 ; \mathrm{df}=8 ;$ Sig. $=0.263$ 
Table 3

Logistic Regression Analysis of Zakah on Employment Income ( $\mathrm{N}=348)$

Using Attitude Summative Single Score

\begin{tabular}{|c|c|c|c|c|c|}
\hline & & \multicolumn{4}{|c|}{ Classification Table } \\
\hline & \multirow[b]{3}{*}{ Observed } & & \multicolumn{3}{|c|}{ Predicted } \\
\hline & & & \multicolumn{2}{|c|}{ Payment } & \multirow{2}{*}{$\begin{array}{c}\text { Percentage } \\
\text { Correct }\end{array}$} \\
\hline & & & Yes & No & \\
\hline \multirow[t]{3}{*}{ Step 1} & Payment & & & & \\
\hline & & Yes & 206 & 23 & 90.0 \\
\hline & Overal Percentage & No & 34 & 82 & $\begin{array}{l}.70 .7 \\
835\end{array}$ \\
\hline
\end{tabular}

a Constant is included in the model.

b The cut value is .500

Variables in Equation

\begin{tabular}{lccccccc} 
& $\begin{array}{c}\text { Coefficient } / \\
\text { Expected }\end{array}$ & $\mathbf{B}$ & $\begin{array}{c}\text { Standard } \\
\text { Deviation }\end{array}$ & Wald & df & Sig. & Exp(B) \\
\hline $\mathrm{X}_{1}(1)$ & $\beta_{1} /-$ & .012 & .342 & .001 & 1 & .973 & .988 \\
$\mathrm{X}_{2}$ & $\beta_{2} /+$ & .031 & .029 & 1.142 & 1 & .285 & 1.031 \\
$\mathrm{X}_{3}$ & $\beta_{3} /-$ & .014 & .076 & .031 & 1 & .859 & 1.014 \\
$\mathrm{X}_{4}$ & $\beta_{4} /+$ & .00012 & .00025 & .215 & 1 & .643 & 1.000 \\
$\mathrm{X}_{5}$ & $\beta_{5} /+$ & .243 & .049 & 24.151 & 1 & $.000^{* *}$ & 1.275 \\
$\mathrm{X}_{6}$ & $\beta_{6} /+$ & -.013 & .062 & .045 & 1 & .831 & .987 \\
$\mathrm{X}_{7}$ & $\beta_{7} /+$ & -.044 & .048 & .839 & 1 & .360 & .957 \\
$\mathrm{X}_{8}$ & $\beta_{8} /+$ & .043 & .018 & 5.794 & 1 & $.016^{*}$ & 1.044 \\
$\mathrm{X}_{9}$ & $\beta_{9} /+$ & .147 & .035 & 17.980 & 1 & $.000^{* *}$ & 1.158 \\
$\mathrm{X}_{10}$ & $\beta_{10} /+$ & -.051 & .025 & 3.992 & 1 & $.046^{*}$ & .951 \\
$\mathrm{X}_{11}$ & $\beta_{11} /+$ & .185 & .078 & 5.604 & 1 & $.018^{*}$ & 1.203 \\
$\mathrm{~A}_{1}$ & $\beta_{12} /+$ & .162 & .239 & .460 & 1 & .498 & 1.176 \\
$\mathrm{~A}_{2}$ & $\beta_{13} /+$ & 419 & .204 & 4.206 & 1 & $.040^{*}$ & 1.520 \\
$\mathrm{~A}_{3}$ & $\beta_{14} /+$ & .562 & .168 & 11.239 & 1 & $.001^{* *}$ & 1.755 \\
$\mathrm{~A}_{4}$ & $\beta_{15} /+$ & .750 & .178 & 17.724 & 1 & $.000^{* *}$ & 2.117 \\
$\mathrm{~A}_{5}$ & $\beta_{16} /+$ & -.142 & .168 & .716 & 1 & .397 & .868 \\
Constant & & -8.534 & 1.736 & 24.159 & 1 & .000 & .000 \\
\hline$X_{1}=$ & & & & & & & \\
\hline
\end{tabular}

$X_{*}(1)=$ Male

Model Summary: $-2 \mathrm{~L} L=266.862 ;$ Cox \& Snell $\mathrm{R}^{2}=0.396 ;$ Nagelkerke $^{2}=0.549$

Hosmer and Lemeshow Test: Chi-squre $=18.501 ; \mathrm{df}=8 ;$ Sig. $=0.018$ 
The above findings were found reasonably consistent with the results produced from the pilot study. The score of each component above was recomputed and bivariate correlation analysis was then applied to see the correlation between components. Each correlation coefficient between components was found significant at $\mathrm{p}<0.05$. Thus, together with the above findings and reasonable consistency with the results of the pilot study, the measures of attitude construct in the instrument have construct validity.

\section{Single Scores}

Table 2, on page 56, shows the results of multivariatelogistic regression analysis, which includes the variable attitude, using single score. The Hosmer and Lemeshow Chi-Square of 10.03 with 8 degrees of freedom indicate that the model is not significant at $\mathrm{p}<0.05$ (Sig.=0.26). Overall, the model does not have a good fit. The interpretation on the relationship between independent variables and the dependent variable (i.e. payment of zakah) is impaired, although some of the independent variables show significant relationship. The relationship between the payment of zakah and other independent variables is moderately strong as shown by Cox and Snell $R^{2}=0.37$ and Nagelkerke $R^{2}=0.51$. The classification table shows that the above compliance model is expected to predict at $80 \%$ as correct.

\section{Multidimensional Scores}

Table 3, on page 57, shows the results of regression analysis when each of the attitude components (extracted from the factor analysis) is treated as an independent variable. The Hosmer and Lemeshow Chi-Square of 18.50 with
8 degrees of freedom indicate that the model is significant (Sig.=0.018), meaning that, overall, the model has a good fit. The relationship between the probability of paying zakah and the independent variables is moderately strong as shown by Coxand Snell $R^{2}=0.4$ and Nagelkerke $R^{2}=0.55$. The classification table shows that the above compliance model is expected to give $84 \%$ correct prediction. Variables $\mathrm{X}_{5}, \mathrm{X}_{8}$, $\mathrm{X}_{9}, \mathrm{X}_{10}, \mathrm{X}_{11}, \mathrm{~A}_{2}, \mathrm{~A}_{3}$, and $\mathrm{A}_{4}$ were found significantly associated with the payment of zakah.

Recall that variables $\mathrm{A}_{1}$ through $\mathrm{A}_{5}$ represent the components of attitude (Table 3 ). Three of these components are significantly related to the payment of zakah in a positive direction $(\mathrm{p}<0.05)$. The three significant components include the Positive Acceptability $\left(\mathrm{A}_{2}=\right.$ Component 1$)$, Uncertain Acceptability $\left(\mathrm{A}_{3}=\mathrm{Com}\right.$ ponent 3$)$, and Conditional Acceptability $\left(\mathrm{A}_{4}=\right.$ Component 4). Accordingly, one unit of increase in the Positive Acceptability is related to an increase about 0.42 odds log in the payment of zakah, ceteris paribus. Similarly, one unit of increase in the Uncertain Acceptability, increases the probability of payment by $56 \%$. Further, one unit of increase in the Conditional Acceptability is associated to $76 \%$ increase in the probability of payment of zakah. The other two components i.e. General Acceptability (Component 2) and Technical Acceptability (Component 5 ) are not significant.

Based on the second outcome, the model is expressed as:

$$
\begin{aligned}
\text { Logit (payment) }= & -8.53+0.012 X_{1}+0.031 X_{2} \\
& +0.014 X_{3}+0.00012 X_{4} \\
& +0.24 X_{5}-0.013 X_{6}-0.044 \\
& X_{7}+0.043 X_{8}+0.15 X_{9} \\
& -0.05 X_{10}+0.19 X_{11}+0.16
\end{aligned}
$$


$\mathrm{A}_{1}+0.42 \mathrm{~A}_{2}+0.56 \mathrm{~A}_{3}$ $+0.75 A_{4}-0.14 A_{5}$

where,

$P=$ Payment (coded as " 1 " for paymentand " 0 " fornon-payment)

$X_{1}=$ Gender

$X_{2}=$ Age

$X_{3}=$ Number of dependants

$X_{4}=$ Income

$X_{5}=$ Perception on Zakah Law

$X_{6}=$ Perception on Zakah En forcement

$X_{7}=$ Perception on Fairness

$X_{8}=$ Perceived Service Quality

$X_{9}=$ Promotional Exposure

$X_{10}=$ Religiosity Index

$X_{11}=$ Knowledge

$\mathrm{A}_{1}=$ Attitude Component General Acceptability

$\mathrm{A}_{2}=$ Attitude Component - Positive Acceptability

$\mathrm{A}_{3}=$ AttitudeComponent-Uncertain Acceptability

$\mathrm{A}_{4}=$ Attitude Component - Conditional Acceptability

$A_{5}=$ Attitude Component - Technical Acceptability

Comparison of Outcomes

Table 4, on page 59, shows an extract from the two results of Multivariate Logistic Regression given in Table 2 and Table 3. Overall, the application of multidimensional scores of attitude provides better result than the single score. The Hosmer and Lemeshow significant test of goodness of fit improved from 0.26 (not significant) to 0.018 (significant at $\mathrm{p}<0.05$ ). Both indicators of the strength of the relationship between independent variables and dependent variables i.e. Cox\&Snell $R^{2}$ and Nagelkerke $R^{2}$ also show some improvement. Further, the use multidimensional factor scores provides better prediction of the probability of zakah payment and the model is more informative as more independent variables were found to have significant relationship with the dependent variable.

\section{DISCUSSION}

The first objective of this study is achieved as the results from the factor analysis show that there are five components or dimensions in the variable attitude towards zakah on employment income. The five components were named as General Acceptability, Positive Acceptability, Uncertain Acceptability, Conditional Acceptability, and Technical Acceptability. These results also confirm the Attitude Latitude Theory, which was suggested by Sherif and Hovland (1961). According to them, attitude latitude' is a range of attitudinal positions, which a person may accept or reject concerning a given issue. Thus, in this study, we observed that a similar situation existed with respect to attitude towards zakah on employment income. The results show a range of attitudinal positions possessed by the Muslim employees. The range was from the positive position (such as Positive Acceptability) to the negative position (such as in Technical Acceptability). Further, the cognitive and affective aspects of attitude were found to be intertwined. This is similar to what has been stressed by Sherif and Hovland (1961). 
Table 4

A Comparison of Between the Single and Multidimensional Scores

\begin{tabular}{lcc}
\hline \hline & Single Scores & Multidimensional Scores \\
\hline Goodness of fit-Hosmer and Lemeshow Test & Sig. $=0.263$ & Sig. $=0.018$ \\
The strength of the relationship between & & \\
$\begin{array}{l}\text { independent variables and dependent variable } \\
- \text { Cox \& Snell } \mathrm{R}^{2}\end{array}$ & 0.37 & 0.40 \\
$-\quad$ Nagelker $\mathrm{R}^{2}$ & 0.51 & 0.55 \\
Prediction Accuracy & $80 \%$ & $84 \%$ \\
No. of variables with significant relationship & 5 & 8 \\
\hline \hline
\end{tabular}

The results produced from logistic regression analyses fulfilled the second objective of this paper. The present study, which deals with a complex attitude variable, provides a useful insight to researchers on the need to use multidimensional factor scores rather than a straight-forward "unidimensional summated rating." The use of multiple score analysis seemed to yield more informative and improved results. This findings confirm the suggestion made by Mueller (1986) that complex attitude object should be studied by decomposing the object or issue into smaller and less complex elements on the basis of component parts, specific functions, or particular contexts. Thus, in this study the issue of attitude towards zakah on employment incomehas been decomposed into five different components and tested against the compliance behaviour of payment of zakah.

The logistic regresion analysis (Table 3) further shows that three out of five components of attitude are significantly related to the com pliance behaviour. The first related component i.e. Positive Acceptability supports the contention that compliance behaviour does rely on positive attitude (Silver, 1995). It appears that those who have positive attitudes towards zakah on employment income, have a strong tendency to comply with the zakah payment. This situation is considered normal and consistent with the cognitive theory. However, it is quite a surprise to notice that the uncertain position of attitude is also positively associated with the payment of zakah $(\mathrm{Sig}=0.000)$. One reason for this is that many zakah payers are conservative towards issues related to religion. They prefer to pay, although the matter is not clear to them. By doing so, they feel that they are on the safe side in case the matter is actually found to be obligatory. Another related component is the Conditional Acceptability. Under this form of attitude, the compliance of zakah payment would probably increase if certain circumstances are present. Such circumstances include: stern action taken by the authorities 
against those who fail to pay zakah; availability of the salary deduction scheme; and the uniformity of decision to impose zakah on employment income in all states of Malaysia. This is consistent with the equity theory, in which the state of fairness is observed by the people in the process of complying wth zakah payment.

Besides the variable attitude, other variables were also found significantly associated with the payment of zakah. These include perception on zakah law; perceived service quality; exposure to the promotional activities; religiosity; and knowledge. However, this paper focuses only on the methodological issue of the attitude variable. Thus, other variables are not discussed further in this paper.

This study may provide useful insights to policy makers or zakah authorities. It has - shown that the attitude based on general acCeptability is simply insufficient to induce Muslim employees to comply with the fatwa of zakah on employment income. Better strategies have to be designed and implemented to inculcate the attitude based on positive acceptability among qualified Muslim employees. Furthermore, stern action or enforcement should be implemented as it forms part of the stimulus in the attitude based on conditional acceptability.

The study of attitude towards zakah on employment income can be further investigated. The present study was conducted among qualified employees in the federal government office in the state of Kedah. Future research should be conducted to include qualified employees from all sectors. In addition, a comparative research should be carried out to gauge any significant difference in attitude among Muslims between the states in Malaysia. The results of such studies may enhance the compliance theory of zakah and assist the authorities in their efforts to boost the compliance level.

\section{CONCLUSION}

As expected, atitude towards zakah on employment income is a complex variable in nature. This complexity, however, can be divided into smaller or less complex elements. By applying principal component analysis with varimax rotation, the attitude was divided into five different components which were named respectively as General Acceptability, Positive Acceptability, Uncertain Acceptability, Conditional Acceptability, and Technical Acceptability. The names were given appropriately by observing the common characteristics of items clustered in each respective component.

In the logistic regression model, the use of the multiple attitude variable seem to yield more informative and better results than using a single summative score of attitude. The improved results show that among the five components of attitude, three of them i.e. positive, uncertain, and conditional positions of attitude were found to have significant influence on the payment of zakah. Thus, the results provide a useful insight to authorities that any attempt to improve the level of compliance of zakah payment should begin with improving the attitude of eligible Muslim employees towards zakah on employment income. 


\section{BIBLIOGRAPY}

Andreoni, J., Errard, B. \& Feinstein, J. (1998).

Tax compliance. Journal of Economic Literature, 36(2), 818-860.

Bennett, S. \& Bowers, D. (1976). An Introduction to Multivariate Techniques for Social and Behavioral Sciences. New York: John Wiley and Sons.

Bobek, D. (1997). Tax fairness : How do individuals judge fairness and what effect does It have on their behavior. Ph.D. Dissertation, University of Florida, Gainesville.

Churchill, G.A. Jr. (1979). A paradigm for developing better measures of marketing constructs. Journal of Marketing Research, 16(1), 64-73.

Coakes, S.J. \& Steed, L.G. (1999). SPSS Analysis Without Anguish. Brisbane, Australia:John Wiley \& Sons.

Dyer, J.E \& Osborne, E.W. (1996). A factor analysis of attitudes of Illinois guidance counselors towards agriculture programs. From http://www.ssu.missouri.edu/ SSU/AGED/naerm/s-d-4.htm.

Elliot, A., Timothy D.W. \& Robin, M.A. (1999). Social Psychology (3rd. ed.). New York: Longman.

Eriksen, K. \& Fallan L. (1996). Tax knowledge and attitudes toward taxation: a report on a quasi experiment. Journal of Economic Psychology, 17(3), 387-402.
Fischer, C.M., Wartick, M., \& Mark, M.M. (1992). Detection probability and taxpayer compliance : A review of the literature. Journal of Accounting Literature, 11, 1-46.

Hair, et al. (1995). Multivariate Data Analysis with Readings (4th ed.). Englewood Cliffs: Prentice-Hall.

Hajah Mustafa, M.H. (1996). An evaluation of the Malaysian tax administrative system, and taxpayer's perceptions towards assessment system, tax law fairness, and tax law complexity. Ph.D. Dissertation, Universiti Utara Malaysia, Malaysia.

Jackson, B.R. \& Milliron, V.C. (1986). Tax compliance research: findings, problems and prospects. Journal of Accounting Literature, 5, 125-165.

Johnson, R. A. \& Wichern, D. W. (1992). Applied Multivariate Statistical Analysis (3rd ed.). Englewood Cliffs: Prentice-Hall.

Kim, J.O. \& Mueller, C.W. (1978). Factor Analysis : Statistical Methods and Practical Issues. Beverly Hills: Sage Publication.

Lawver, D.E. \& Fraze,S.D. (1996). Factor analysis of variables related to student attitudes and perceptions concerning agricultural mechanics laboratory safety. From http://www.ssu.missouri.edu/ SSU/AGED/naerm/s-k-1.htm.

Lewis, A. (1982). The Psychology of Taxation. Oxford: Martin Robertson. 
Menard, S. (1995). Applied Logistic Regression Analysis. London: Sage Publication.

Mueller, D.J. (1986). Measuring Social Attitudes. Columbia University, New York: Teachers College.

Mujaini Tarimin (1995). Zakat penggajian : Satu penilaian terbaru di Malaysia. Tesis $\mathrm{PhD}$, Universiti Malaya, Malaysia.

Nunnally, J.C. (1978). Psychometric Theory (2nd ed.). New York: McGraw-Hill.

Oskamp, S. (1991). Attitudes and Opinions (2nd ed.). Englewood Cliffs: Prentice-Hall.

Peter, J.P. (1981, May). Construct validity : A review of basic issues and marketing practices. Journal of Marketing Research, 13, 527.

Sekaran, U. (2000). Research Methods for Business. New York: John Wiley \& Sons.
Sherif, M. \& Hovland, C.I. (1961). Social judgement: Assimilation and contrast effects in communication and attitudechange. New Haven: Yale University Press.

Silver, D.P. (1995). Tax compliance and taxpayer attitude : Over the last forty years, this country has experienced a taxpayer revolt. National Public Accountant, 40 (11), 32-35.

Spicer, M. W. \& Lundstedt, S. B. (1976). Understanding tax evasion. Public Finance, 31 (2), 295-305.

Sutinen, J.G. \& Kuperan K. (1999). A socioeconomic theory of regulatory compliance. International Journal of Social Economics, 26 $(1,2,3), 174-193$.

Tayib, M. (1998). The determinants of assessment tax collection : The Malaysian local authority experience. PhD. Dissertation, University of Glamorgan. 